second year students. Qualitative data were analysed using the applied thematic analysis methodology.

Result Computer anxiety was significantly higher for first year students compared to second-year students $(t=4.08, p<0.001)$. Lecturers also indicated barriers to using on-line technology for teaching.

Discussion Blended learning, a useful teaching strategy, has the potential to advance the $\mathrm{OHN}$ specialisation programme at DUT through the numerous opportunities for collaborative learning that the online technology affords. However, the challenges faced by both lecturers and students need to be addressed through focused interventions to ensure the optimal use of this teaching/learning strategy.

\section{ADVANCING OCCUPATIONAL AND ENVIRONMENTAL HEALTH NURSING CONTINUING EDUCATION RESOURCES THROUGH TECHNOLOGY}

MG Ryan*. President, American Association of Occupational Health Nurses (AAOHN), Chicago, Illinois, USA

\subsection{6/oemed-2018-ICOHabstracts. 1001}

Introduction This presentation will demonstrate, highlight, and review AAOHN's global reach through technology and social media that provides 24 hour access to occupational and environmental health nursing standards of practice and continuing education resources.

Methods A retrospective literature and organisational review was conducted to determine Global Health 2035 initiatives that occupational and environmental health nurses (OHNs) can use to demonstrate an impact through existing and projected future resources.

Result AAOHN, the premier association of OHNs, ensures continuing education resources not only for practice, but also for professional board certification. To accomplish this, there is one annual national conference along with a global summit offered every 3 years with the 5 th gobal summit scheduled for 2020. Since 2016, a virtual conference option has been provided with on-line live-streaming. Online educational live/ archived webinars and standards of practice are available free with membership or for a nominal fee. Through $\mathrm{NIOSH}$ grants and in conjunction with organisation expert collaboration, free respiratory protection program modules (3rd and 4th modules expected Fall 2017) are accessible at www.aaohn. org. AAOHN's journal, Workplace Health and Safety, provides research, case studies, and continuing education modules for purchase. Additionally, collaboration with other organisations advances $\mathrm{OHN}$ practice and has expanded current grant opportunities for further educational resources both in Hepatitis $\mathrm{C}$ and Infection Prevention and Control. Utilising these AAOHN resources, along with opportunities to share and publish current research, OHNs are prepared to offer and provide preventive services under new/changing health care systems to meet or exceed Global Health 2035 initiatives.

Conclusion AAOHN's innovative continuing education technology resources continue to provide OHNs with up-to-date tools for:

- preparing for professional board certification;

- ensuring that worker health and safety programs and services meet or exceed Global Health 2035 initiatives; and

- meeting future health care challenges.

\section{8 PERMANENT EDUCATION PRACTICE IN OCCUPACIONAL} HEALTH: AN INTEGRATIVE REVIEW

${ }^{1}$ Ellen Silva da Anunciação, ${ }^{1}$ Cristiane Helena Gallasch*, ${ }^{1}$ Magda Guimarães de Araujo Faria, ${ }^{1}$ Eugenio Fuentes Pérez Júnior, ${ }^{1}$ Priscila Cristina da Silva Thiengo, ${ }^{2}$ Luciana Valadão Alves Kebian. 'Rio de Janeiro State University, Rio de Janeiro, Brazil; ${ }^{2}$ Instituto Federal de Educação, Ciência e Tecnologia Fluminense, Rio de Janeiro, Brazil

\subsection{6/oemed-2018-ICOHabstracts. 1002}

Introduction Permanent education in health has not the aim of training health professionals, but proposes to bring them together the team to build knowledge, valuing the concept of teaching-learning through a new policy proposal to improve work processes.

Objective To analyse experiences and strategies of continuing education about workers' health in scientific publications from the last ten years.

Method It is a literature integrative review, from 2006 to 2016, with search in Virtual Health Library and Scientific Eletronic Library Online databases. All the six steps of methodology were developed: defining research question - What strategies and experiences of permanent education for workers' health have been described in the literature?; determining search strategy, with Occupational health, Continuing education and Permanent education as descriptors; categorising studies; reading papers to determine those containing results; discussion of the results; and presentation of the integrative review.

Results Eight articles were selected and analysed. After applying all steps of integrative review, data was classified in two categories: Strategies of continuing education and Experiences of continuing education.

Conclusion There is a lack of scientific and technical knowledge about Strategies of continuing education, being an important cause of difficulty to develop the work process, which is often aimed to collective strategies and always seeking the transmission of knowledge. About Experiences of continuing education, it's observed the development of guidelines directed to the ergonomic risks, with participation of workers.

\section{ANALYSIS OF HEART RATE VARIABILITY DURING THE INHALATION OF A DIFFUSED AROMA}

${ }^{1}$ Yuriko Hachiya*, ${ }^{2}$ Minori Shibata, ${ }^{3}$ Hiroshi Inujima. ${ }^{1}$ School of Health Sciences Occupational and Community Health Nursing, University of Occupational and Environmental Health, Japan, Fukuoka, Japan; ${ }^{2}$ Department of Otorhinolaryngology Head and Neck Surgery, School of Medicine, University of Occupational and Environmental Health, Japan, Fukuoka, Japan; ${ }^{3}$ Graduate School of Information, Production and Systems, Waseda University, Fukuoka, Japan

\subsection{6/oemed-2018-ICOHabstracts. 1003}

Introduction Stress-related disorders, such as depression, psychosomatic disorders and anxiety neurosis, are common and increasing in the workplace. Aromas have ataractic and sedation effects on the parasympathetic nerves. They also affect the feelings of fatigue from stress by stimulating the central nervous system. The purpose of this study is to examine the effect of an olfactory stimulus on changes in a physiological index. Using aromas during the loading of stress, we measured beat-to-beat interval ( $\mathrm{R}-\mathrm{R}$ interval) times from electrocardiogram (ECG) recordings.

Methods The subjects in our study were 3 male medical university students (subjects' codes were A, B and C). After 